\title{
Precision tests of geodetic centring equipment
}

\author{
Filip Dvořáček \\ Czech Technical University in Prague \\ Department of Special Geodesy \\ Czech Republic \\ filip.dvoracek@fsv.cvut.cz
}

\begin{abstract}
The paper introduces testing procedures of several different geodetic centring devices performed mostly at the laboratory of the Research Institute of Geodesy, Topography and Cartography. Functional construction characteristics of a spherically mounted retroreflector Leica RRR 1.5", rotatable carriers Sokkia AP41 and Leica GZR3 and 12 different geodetic tribraches were examined. Further, a centring displacement instrument developed at the Czech Technical University in Prague, Faculty of Civil Engineering, Department of Special Geodesy, is evaluated in both laboratory and field conditions. For all tests, laser tracker Leica AT401 with a 5 $\mu m$ standard uncertainty of absolute distance measurement, was employed. The main goal of the paper is to verify usability of equipment for precision engineering tasks and eventually to suggest appropriate measurement methodology to compensate design inaccuracies of centring devices.
\end{abstract}

Keywords: precision testing; spherically mounted retroreflector; rotatable carrier; laser tracker Leica AT401.

\section{Introduction}

Initial purpose of the testing of centring equipment was fully practical. Specific geodetic tasks require thorough knowledge of every instrument employed in the measurement process. The aim of the author was to minimize centring errors and to evaluate uncertainties of measurement during calibrations of the Czech state long distances measuring standard Koštice and the National calibration baseline Hvězda. When Leica AT401 is used for calibrations of field baselines, the multiple centring is a significant source of error in an overall uncertainty budget. Even if the absolute laser tracker disposes of the exceptional accuracy concerning the distance measurement [5], its range is limited up to $160 \mathrm{~m}$ in favourable weather conditions.

Although the paper concerns specific types of centring devices, results can be interesting even for readers who do not own the same devices. Not many surveyors are forced to deal with the high precision such as discussed in the paper but occasionally they could need to know about general design limits of standard geodetic centring equipment. Moreover, the article presents a quick way of the testing which uses advantages of the Leica AT401. The only real prerequisite to run the tests is to own or has access to an appropriate laser tracker and controlling software. Other conventional methods, including precise angle measurement and the use of a laboratory interferometer, are usually much more time-consuming and laborious [6]. 
It is necessary to point out that most of all tests are focused on evaluating the precision in a single dimension. If a centring device is pointed out to face the surveying instrument (e.g. laser tracker, total station), the longitudinal direction of the line of sight is placed emphasis on. The knowledge of the transverse direction error was not important for further use of equipment for purposes of calibrating field length baselines. Also it should be noted, that tests deal with precision and centring repetitions, not with accuracy. While accuracy means overall correctness of the centring above a geodetic point, precision means scattering of results around the mean value regardless of the correctness. To achieve the highest possible accuracy, the same centring device should be always used on the same geodetic point to eliminate shift differences among devices.

\section{Laser tracker Leica AT401}

All observations were performed with the laser tracker Leica AT401 (Fig. 1) owned by the Research Institute of Geodesy, Topography and Cartography (RIGTC). The manufacturer specifies the accuracy according to ASME B89.4.19-2006 standard as standard deviations: $5 \mu \mathrm{m}$ for distance measurement (up to $40 \mathrm{~m}$ range) and $7.5 \mu \mathrm{m}+3 \mu \mathrm{m} / \mathrm{m}$ angular accuracy (0.5") [5]. Standard deviation of $2.5 \mu \mathrm{m}$ should be fulfilled for repeatability of distance measurement according to Leica's own tests (paper attached to the purchased instrument). Experience of the author is even better - even less than $1 \mu \mathrm{m}$ standard deviation can be usually expected for short distances [3]. The performed tests are designed in order to benefit from such a superior precision parameter of the instrument.

All measurements were controlled by an application called ATControl (Fig. 1) [2] which was designed by the author of this paper. The Leica's Tracker Pilot software does not allow userfriendly data saving and the available commercial software Polyworks v.12 does not allow to save measured angels and distances at all. ATControl is a graphical application programmed in Matworks Matlab which enables complete raw data saving and adds many convenient functions for surveyors and metrologists. Furthermore, it enables to eliminate several important firmware errors of Leica AT40x trackers including the error wavelength and the late update of the refractive index of air [4]. However, to achieve the highest possible accuracy, the group refractive index of air was fixed during all tests held in laboratory conditions.
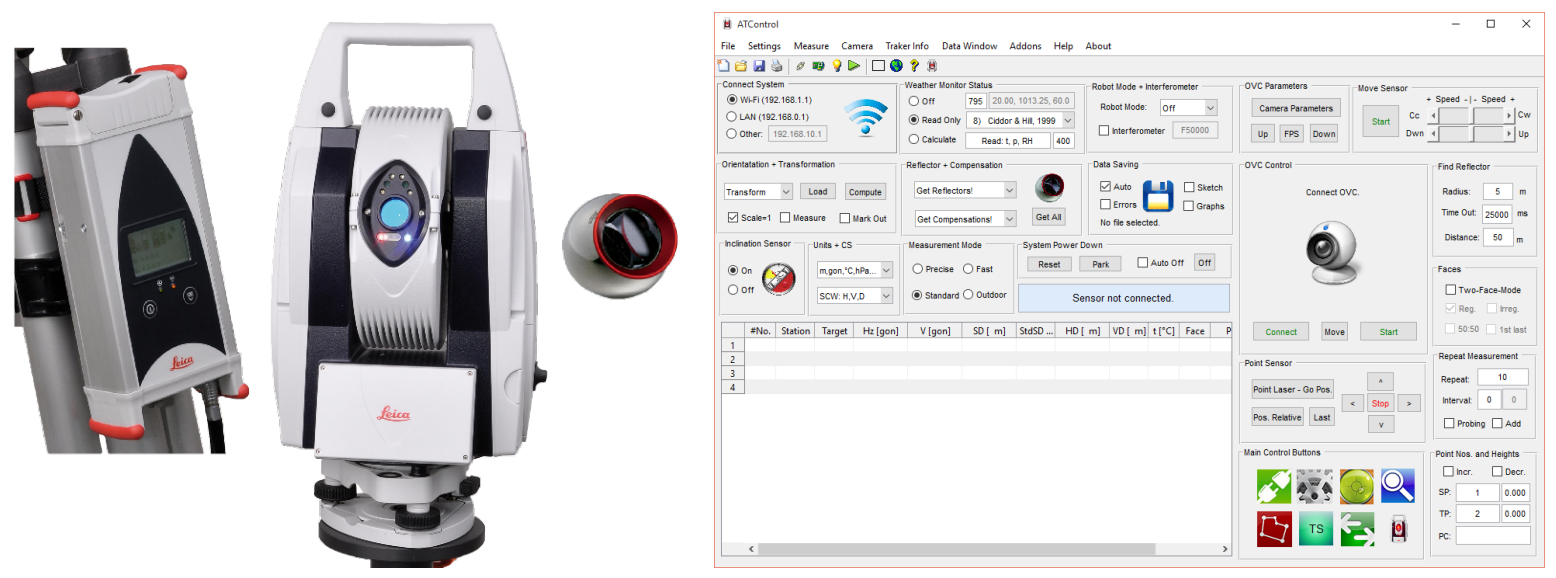

Figure 1: Controller Leica AT400 and sensor Leica AT401 (left); Software ATControl 3.4 (right) 


\section{Performed tests of centring equipment}

\section{Leica RRR1.5" spherically mounted retroreflector}

Spherically mounted retroreflectors (SMR) are manufacturer's answer for customer's demand for accurate geodetic prisms. There are several different types (3 offered by Leica itself) but RRR 1.5" reflector (Red Ring Reflector with $19.5 \mathrm{~mm}$ radius; also at Fig. 6) is the most suitable for surveyors who works with Leica AT40x trackers. As SMRs are state-of-the-art products, it became common for manufacturers to state their accuracy parameters. RRR 1.5in used to have declared $6 \mu \mathrm{m}$ standard deviation of centring of optics but newer model has now $3 \mu \mathrm{m}$ only. This is useful when someone operates several reflectors and does not want to frequently change or possibly mess with different additive constants. In reality, additive constants of our two RRR 1.5" reflectors (old model) differ of $13 \mu \mathrm{m}$.

The shape of the RRR 1.5" reflector should be a ball with a maximum standard deviation of $1.5 \mu \mathrm{m}$. This parameter could be easily verified by a test. Reflector was placed inside a circle nest of Sokkia AP41 carrier and rotated by 50 gon after each set of measurement. Position of the reflector was signalized by the "Leica" sign on the steel cover. Step by step, the reflector was rotated by 50 gon while the centre of the prism always aimed to the laser tracker which measured distances ( 1 face, 3 repetitions). For verification, measurements were performed twice ("There" and "Back"). Maximum deviation from the average distance did not exceed $1.5 \mu \mathrm{m}$ (Fig. 2). However, even more interesting was the finding that the Leica AT401 was easily able to detect changes of the distance which were smaller than $1 \mu \mathrm{m}$. The congruence of both rotation path was surprisingly great and very convincing about the correctness of results. Even if the distance differences caused by placing the RRR 1.5" reflector in the nest of Sokkia AP41 holder should never exceed $2.5 \mu \mathrm{m}$, the position should be always fixed during various precision laboratory measurements (e.g. determination of the additive constant).

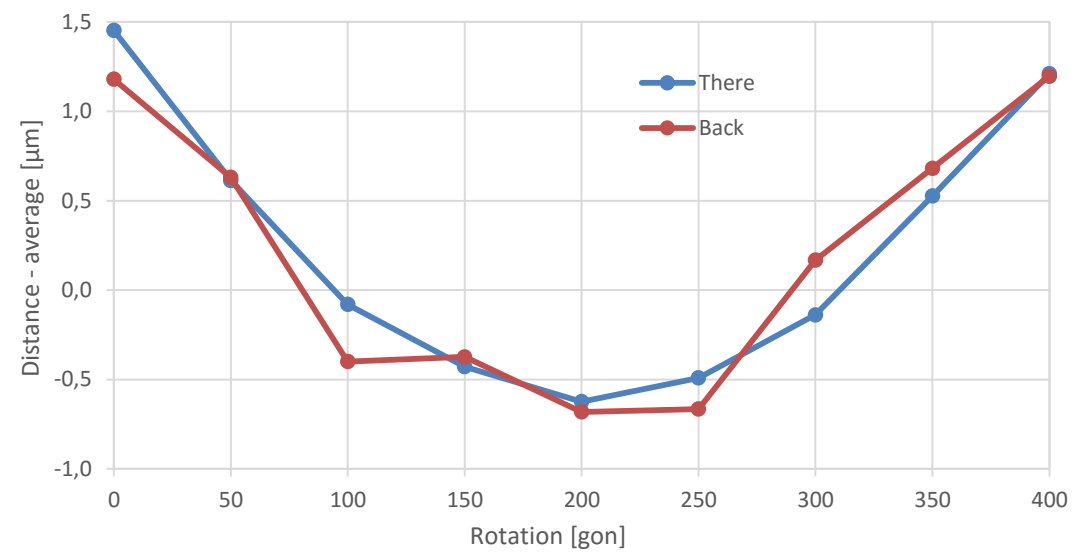

Figure 2: The rotation of Leica RRR 1.5" reflector around the line of sight axis

\section{Sokkia AP41 and Leica GZR3 rotatable carriers}

Sokkia AP41 and Leica GZR3 (Leica GZR3 at Fig. 7) are devices used for centring and horizonting at the Koštice and Hvězda baselines. The original question was if a measurer can variously rotate the devices on forced-centring plates or the position has to fixed. Apart from 


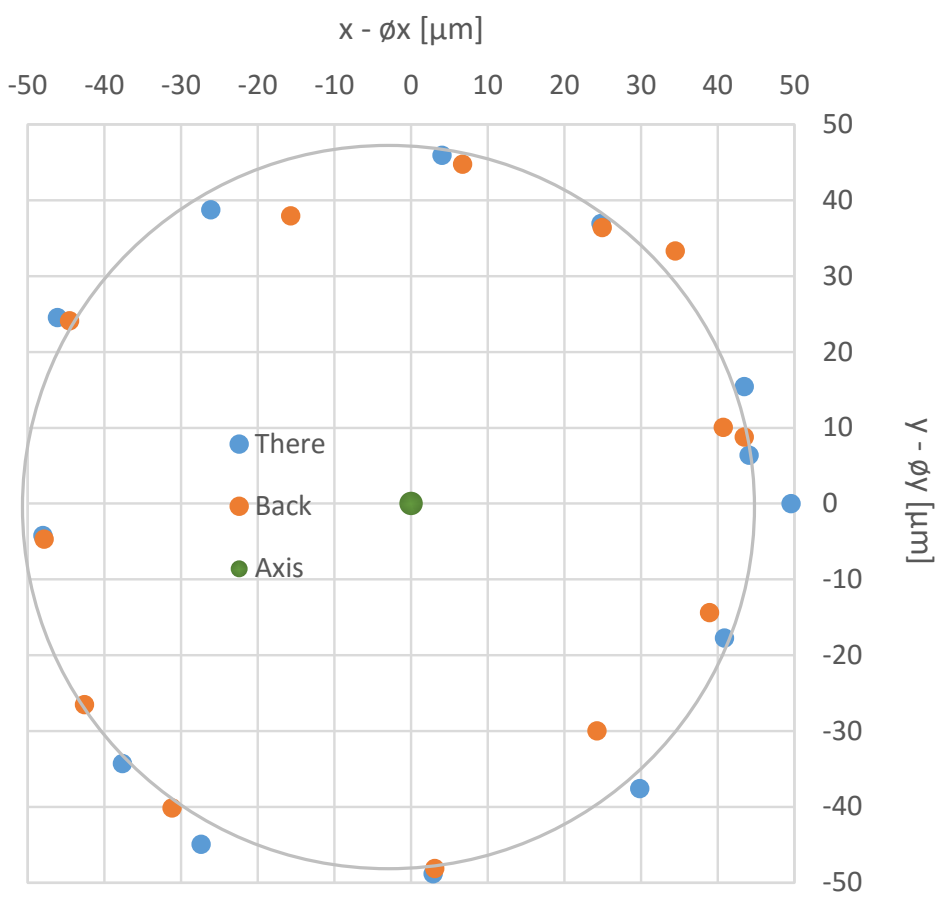

Figure 3: The rotation of Sokkia AP41 around its vertical axis

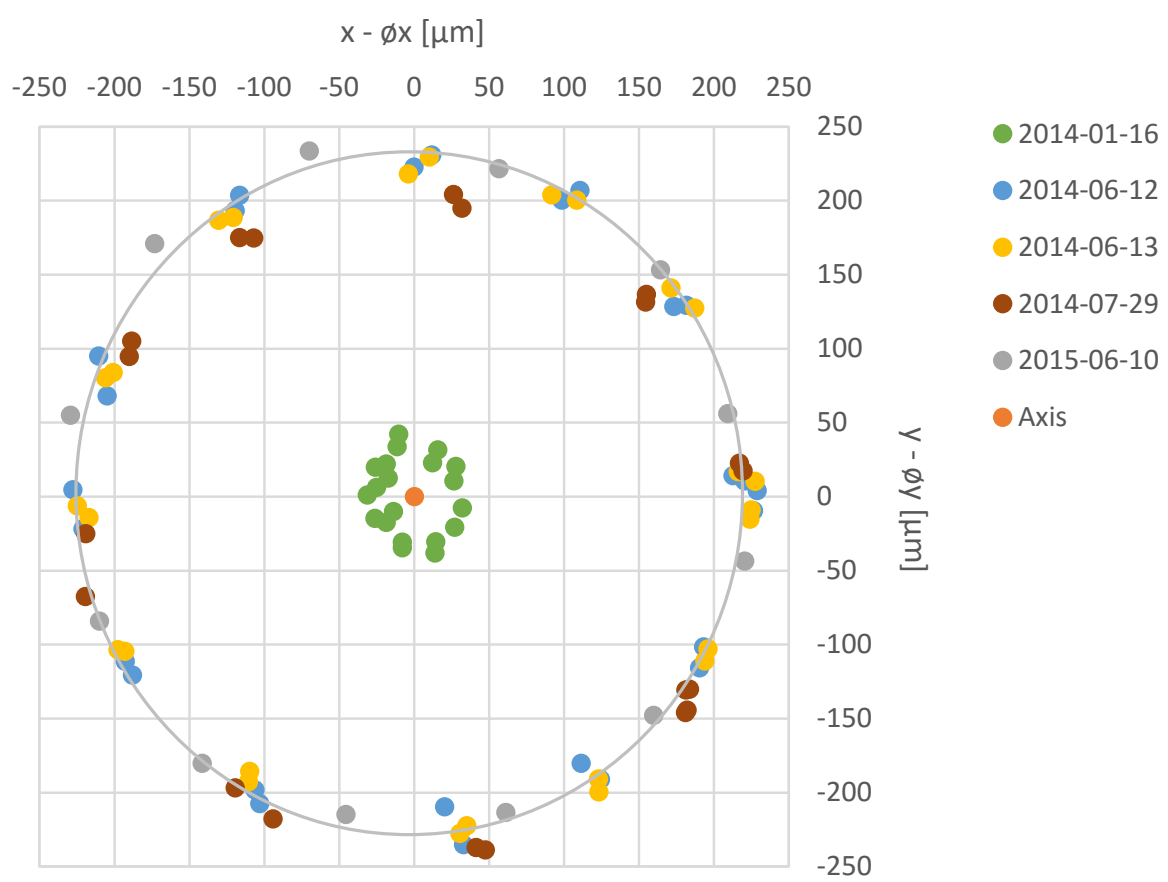

Figure 4: The rotation of Leica GZR3 around its vertical axis 


\section{F. Dvořáček: Precision tests of Geodetic Centring equipment}

a single dimensional distance test (not presented here), also 2D evaluation of measurement, which necessarily employed angle observations, proved to be adequately accurate. Geometrical layout of the test was chosen to be optimal for angle measurement (distance about 5 meters, single level above the floor). 12 positions in spacing of $30^{\circ}$ were signalized with yellow tape around surfaces of the devices and distances and angles were measured by the Leica AT401 (1 face, 1 repetition). $\mathrm{X}$ and $\mathrm{Y}$ coordinates were evaluated in post-processing.

Originally both of the rotatable carriers showed about the same circle radius of about $45-50 \mu \mathrm{m}$ (Fig. 3, Fig. 4). Unfortunately, repeated testing of Leica GZR3 exposed an enormous change of the radius from $45 \mu \mathrm{m}$ to $225 \mu \mathrm{m}$ (Fig. 4). Probably the only reasonable explanation of the results is that the device had to fall down and its construction was distorted. Differences up to $0.1 \mathrm{~mm}$ (and $0.5 \mathrm{~mm}$ respectably) are not tolerable for many engineering works including calibration of geodetic baselines. Therefore, it was decided to keep the devices fixed in a single position (reflector-fixing screw always facing no. 1 pillar) during all measurements. It is also recommended to run this test from time to time to verify the long-term parameters of the carriers, especially the fact if the device did not suffer serious downfall.

When the decision about a fixed position of the rotatable carriers was made, a question about accuracy of pointing followed. It could be eventually computed from known circle radius but it was also verified by a couple of practical tests ( 1 face, 1 repetition). Unexpected behaviour of Sokkia AP41 was detected. Even if random pointing results was performed, values often gathered around two lines which were deviated about $10 \mu \mathrm{m}$ from each other (Fig. 5). Points distribution was not always proportional, sometimes more or less points laid higher or lower. It seems that it depends on the site and amount of carrier's movement before the final position of the device is set. This finding had to be taken into account and the Sokkia AP41 is not further used for the most precise laboratory work where repeated pointing is required. Leica GZR3 showed no signs of such a behaviour. Displayed points were randomly distributed with the standard deviation of a couple of micrometres.

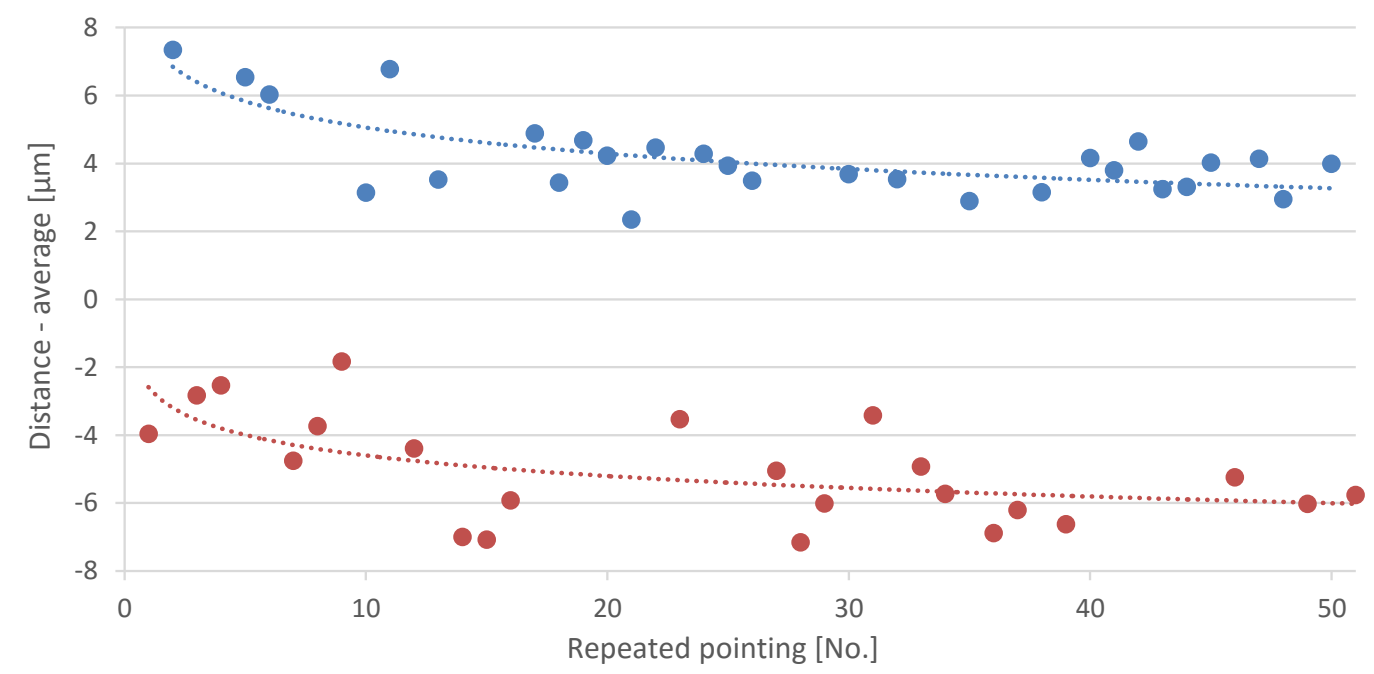

Figure 5: The repeated pointing test of Sokkia AP41

Geoinformatics FCE CTU 15(2), 2016 


\section{Geodetic tribraches}

12 different geodetic tribraches made by Sokkia and Leica are used at the Czech state long distances measuring standard Koštice. It had to be tried if all of them has similar precision during repeated fasten of Sokkia AP41 rotatable carrier. 3 sets of distances from a single station point were measured when tribraches were in 3 different positions (signalized by 3 setting screws). Sokkia tribraches no. 3 and 7 were detected to be "outliers" among others (Fig. 6). No model trademark was found on them but they both were produced with a series number 749 . These two were the only one products of 749 series in our set. Detailed inspection of design of no. 3 and 7 tribraches showed signs of weaker construction (screws joining lower and upper parts) which could easily be the source of observed problems. There is no other way how to eliminate the error of repeated fixing except of choosing the best available tribraches. The tribraches no. 3 and 7 are still in use at the Koštice baseline but at least it was verified that maximum errors do not lay in the longitudinal direction of the etalon.

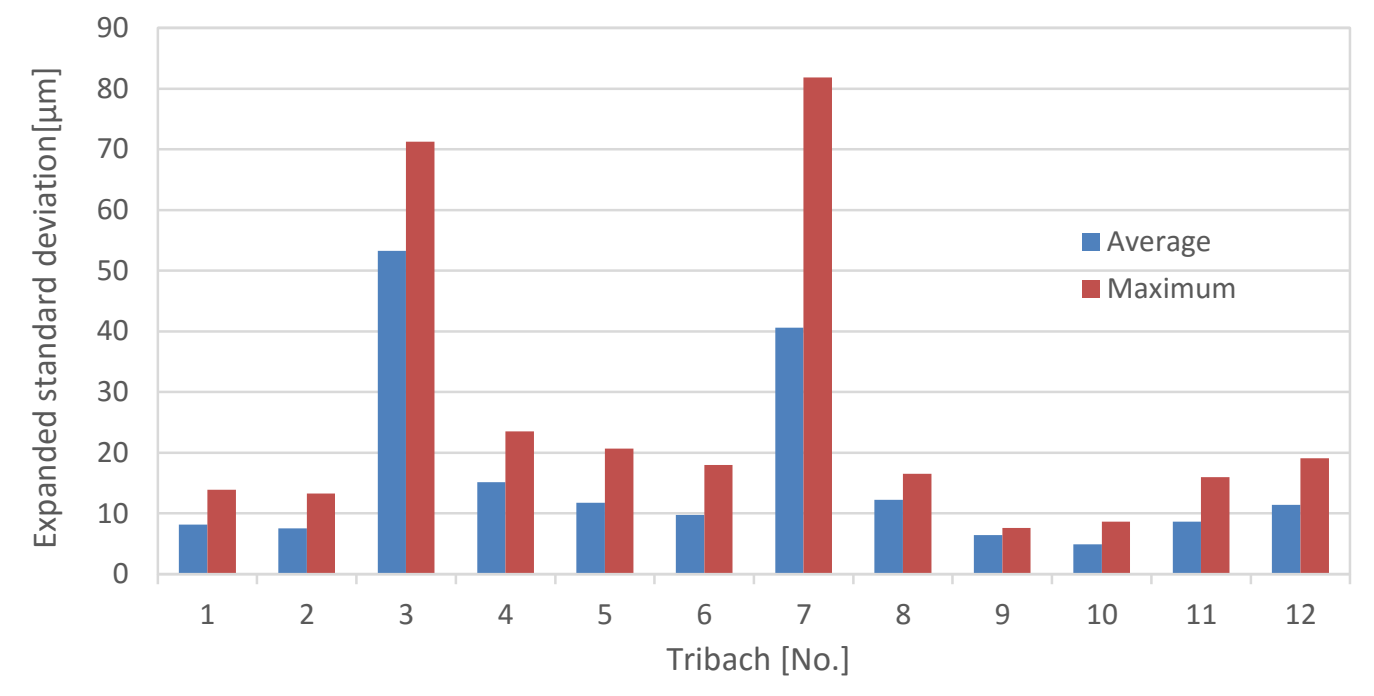

Figure 6: Repeated fastening of Leica AP41 to 12 different tribraches

\section{Repeated levelling}

A couple of tests of repeated levelling were also performed. They concern not only geodetic equipment but they are also significantly by a used methodology and skills of the measurer. The data are needed e.g. when the impact of levelling has to be eliminated to discover an uncertainty of another phenomenon. After each levelling in 4 level positions on the laboratory centring pillar, the horizontal distance tracker-reflector was measured 3 times. If carefully levelled (level 60" / $2 \mathrm{~mm}$ ), both Sokkia AP41 and Leica GZR3 rotatable carriers reached a standard deviation of about $5 \mu \mathrm{m}$ (Fig. 7). The error did not enlarge even when geodetic tribraches were repeatedly fixed on the pillar. Of course, this modification of the test depends on the design of forced centring plates which in this case was part of a laboratory baseline of Faculty of Civil Engineering, Czech Technical University in Prague [1]. 


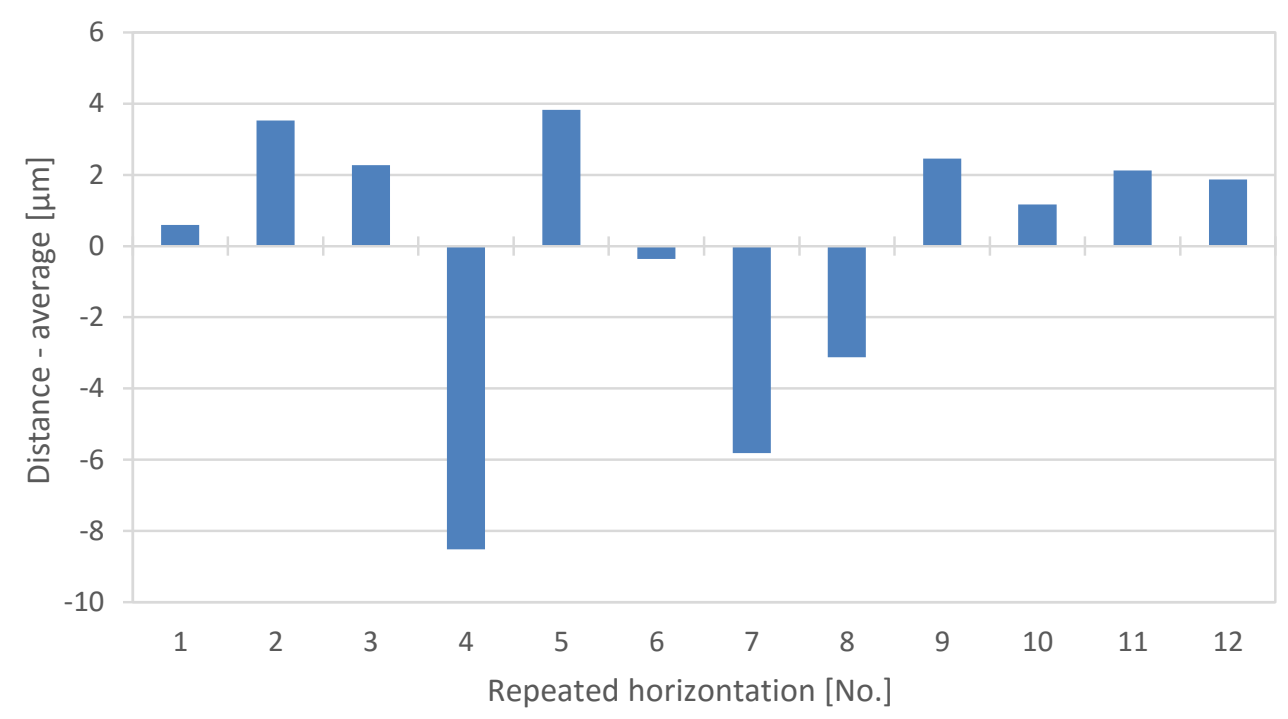

Figure 7: The repeated levelling with Sokkia AP41

\section{Centring displacement device}

Two functional prototypes of centring displacement instrument were developed at the Department of Special Geodesy (example at Fig. 8). Forced centring plates allows fixing geodetic tribraches and mechanical micrometres allows their fine movement. If needed, the amount of movement can be monitored by the mechanical micrometres. Each centring displacement instrument is equipped with a single micrometre and therefore only a longitudinal or transverse displacement is enabled. If movement in both dimensions is needed, two centring instrument can be joint one above another.

Developed devices were tested when a target was placed on a common geodetic tripod about $1.6 \mathrm{~m}$ above ground. Leica GZR3 carrier was used because it implements a hair-cross and not a point in a circle as optical aiming equipment. Transversal line of the hair-cross could be aligned with the edge of a hole in duralumin cylinder (Fig. 9). The diameter of the hole was $1.5 \mathrm{~mm}$ which simulated the targets of the Hvězda baseline. Firstly, repeated centring without repeated levelling was studied in laboratory. The standard deviation of repeated centring was less than $0.050 \mathrm{~mm}$ in every of 3 test (Fig. 10). When repeated levelling was added, the standard deviation enlarged to $0.075 \mathrm{~mm}$ (Fig. 11).

The centring process performed outdoors is very different from a couple of reasons. Tripod stabilization, light conditions, weather and a state of target points can all have important impact. Examples of bad conditions of target points of the Hvězda baseline is given in Fig. 9. During the outdoor centring and levelling test, Leica GZR3 was equipped with the centring displacement equipment whereas Sokkia AP41 was not. Both rotatable carriers were in the same positions during different measurement. A stable target point was regularly observed during the long-lasting test to verify that the instrument maintains unchanged position. All standard uncertainties were about $0,1 \mathrm{~mm}$ which was a great achievement (Fig. 12). Because of damaged target points, the centring displacement device did not cause significant accuracy difference but certainly the centring procedure was quicker and easier. 


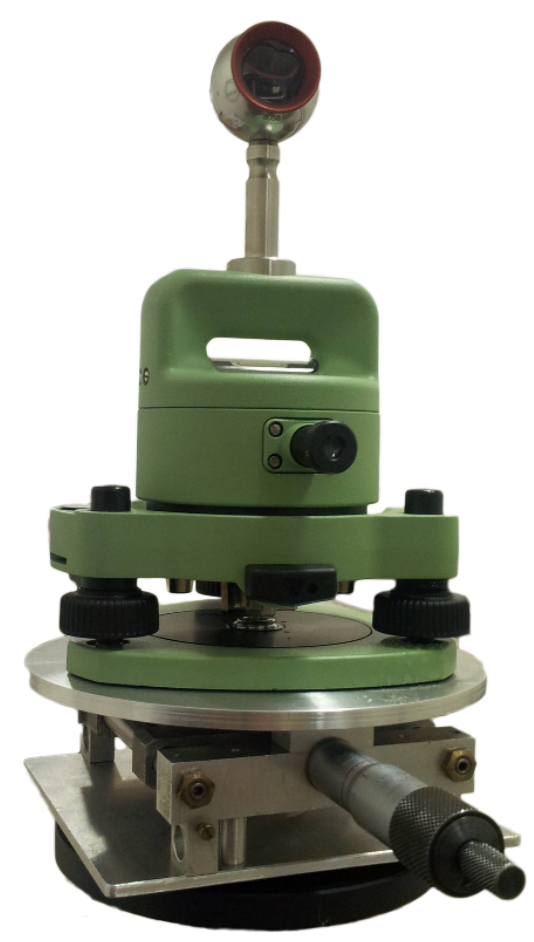

Figure 8: The centring displacement device with Leica tribrach and Leica GZR3
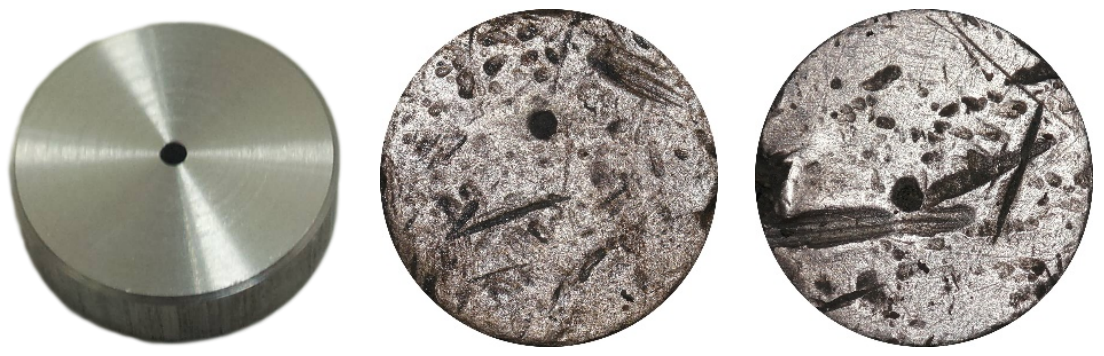

Figure 9: The laboratory target (left) and the field targets (middle: no.1, right: no. 2)

\section{Conclusion}

Laser tracker Leica AT401 proved to be a great instrument for purposes of testing geodetic equipment. Its accuracy, specifically repeatability of the distance measurement, is sufficient even for testing differences less than $1 \mu \mathrm{m}$. Usually it takes a while until a surveyor learn how to "customize" a laser tracker and software for a geodetic use but later the system become very efficient in many surveying tasks. Laboratory interferometer is usually fixed in position but e.g. the Leica AT401 is a very portable instrument.

Leica RRR 1.5" reflector, Sokkia AP41 and Leica GZR3 rotatable carriers and 12 Sokkia and Leica tribraches were successfully tested and important information for estimating further uncertainty budgets has been gained. The developed centring displacement device is a convenient tool in laboratory and it also speed up work in field conditions. Even if the device can be probably potentially bought, the constructed prototype is fully useable and it costed a fraction of a commercial product. 


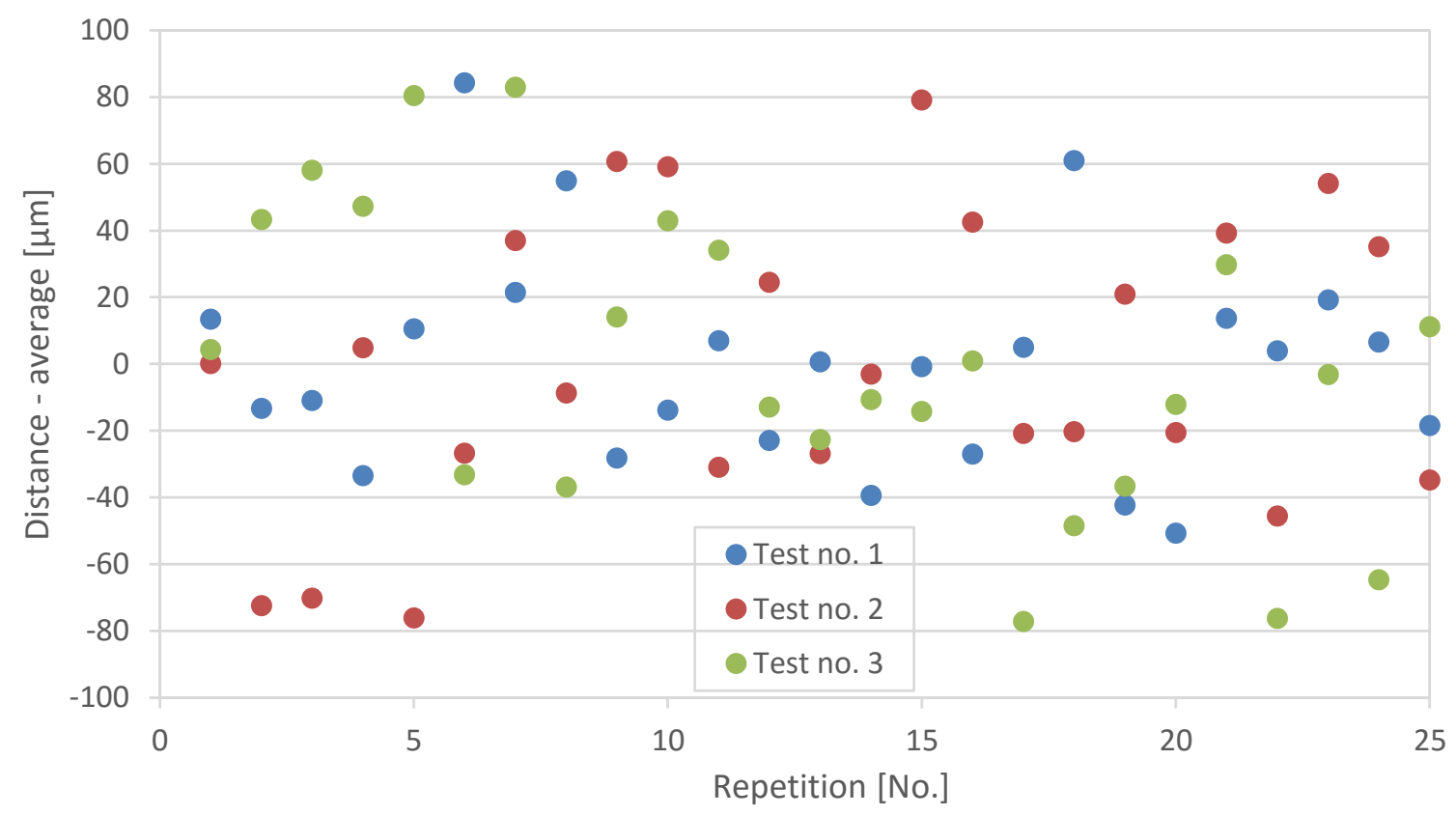

Figure 10: The repeated centring with the centring displacement device

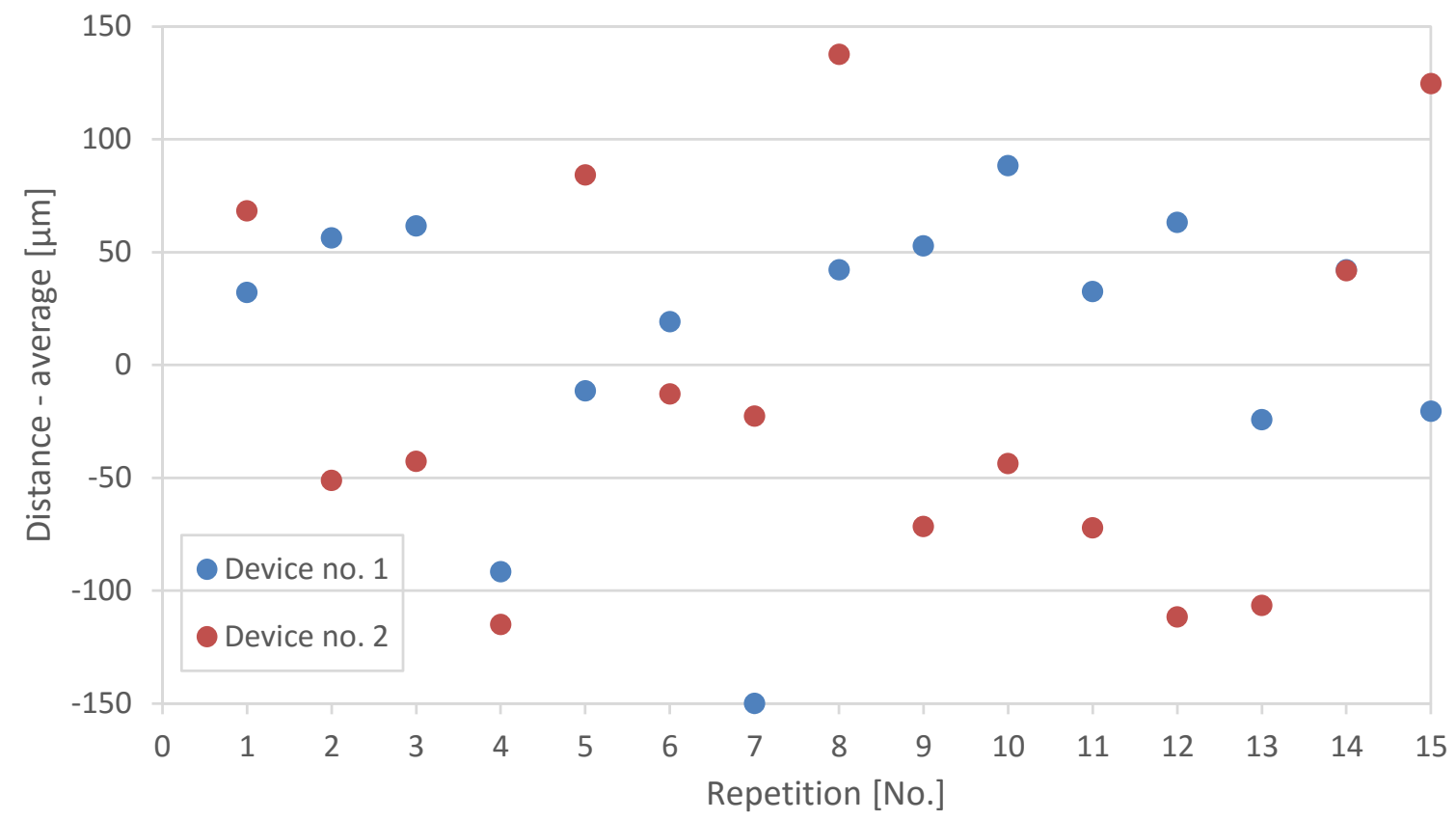

Figure 11: The repeated centring and levelling with the centring displacement devices 


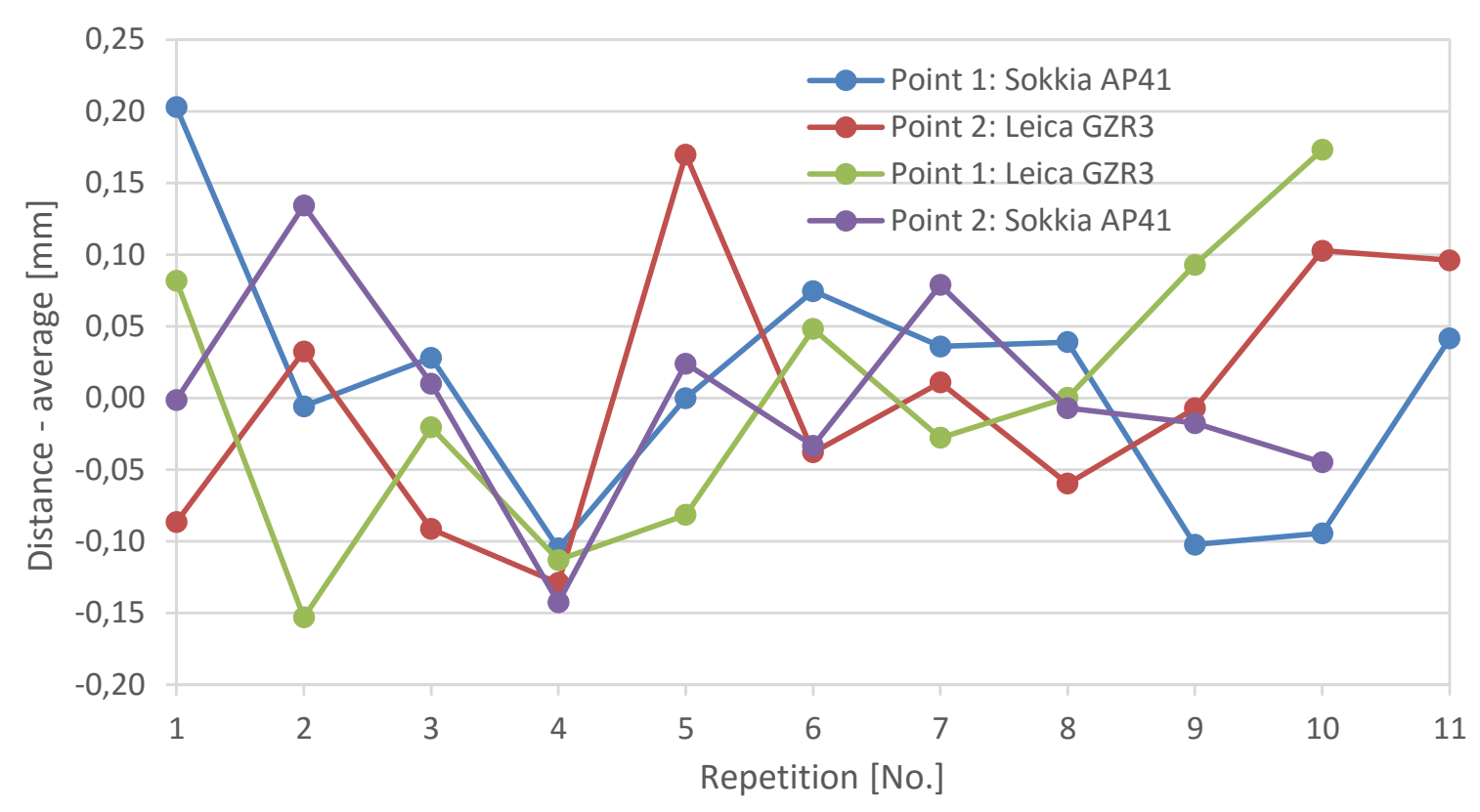

Figure 12: Field test with the centring displacement device

\section{References}

[1] Jaroslav Braun, Filip Dvořáček, and Martin Štroner. "Absolute Baseline for Testing of Electronic Distance Meters". In: INGEO 2014. proceedings of the 6th International Conference on Engineering Surveying : Prague, Czech Republic, April 03-04, 2014. Prague: Czech Technical University, Faculty of Civil Engineering, c2014, pp. 275-280. ISBN: 97880-01-05469-7.

[2] Filip Dvořáček. "ATControl Software for Leica AT40x Laser Trackers". In: Geoinformatics FCE CTU 14.2 (Dec. 2015), pp. 9-20. DOI: 10.14311/gi.14.2.2.

[3] Filip Dvořáček. "Laboratory Testting of the Leica AT401 Laser Tracker". In: Acta Polytechnica vol. 56.issue 2 (2016-04-30), pp. 88-98. ISSN: 1805-2363. DOI: 10.14311/AP. 2016.56 .0088$.

[4] Filip Dvořáček. "System Software Testing of Laser Tracker Leica AT401". In: Geoinformatics FCE CTU 13 (Dec. 2014), pp. 49-57. DOI: 10.14311/gi.13.6.

[5] Leica Geosystems. Leica Absolute Tracker AT401: ASME B89.4.19-2006 Specifications. 2010.

[6] Jan Vaněček and Martin Štroner. "Experimentální určení přesnosti optické centrace". In: Geodetický a kartografický obzor 57/99.3 (2011). ISSN: 1805-7446. 